Artigo

\title{
A apuração dos custos do Serviço de Auditoria Federal do SUS na unidade descentralizada de Santa Catarina com base em um modelo estruturado de custeio
}

\section{The determination of the Federal SUS Audit Service costs in decentralized unit of Santa Catarina based on a structured model costing}

La determinación de los costos de los servicios de auditoría SUS federales en unidad descentralizada de Santa Catarina sobre la base de un modelo estructurado costando

Lucas dos Santos Matos ${ }^{1}$, Fabiano Domingos Bernardo², Altair Borgert ${ }^{3}$, Luiz Alberton ${ }^{4}$.

\footnotetext{
${ }^{1}$ Filiação institucional. Mestrando pelo Program de Pós-Graduação em Contabilidade da Universidade Federal de Santa Catarina, Florianópolis, SC, Brasil.

Correspondência: E-mail: lukxmatos@gmail.com

${ }^{2}$ Filiação institucional. . Mestrando pelo Program de Pós-Graduação em Contabilidade da Universidade Federal de Santa Catarina, Florianópolis, SC, Brasil.

Correspondência: E-mail: fabiano bernardo@hotmail.com

${ }^{3}$ Filiação institucional. Graduado em Ciências Contábeis, , mestre em Administração e doutor em Engenharia de Produção pela Universidade Federal de Santa Catarina. Atualmente é docente do Program de Pós-Graduação em Contabilidade e professor associado iii da Universidade Federal de Santa Catarina, Florianópolis, SC, Brasil.

Correspondência: $\quad$ E-mail: altair.borgert@ufsc.br

${ }^{4}$ Filiação institucional. Graduado em Contabilidade, mestre e douitor Pelo Programa de Pós-Graduação em Engenharia da Produção da Universidade Federal de Santa Catarina, Brasil. Atualmente é docente do Program de Pós-Graduação em Contabilidade e professor associado iii da Universidade Federal de Santa Catarina, Florianópolis, SC, Brasil.

Correspondência: $\quad$ E-mail: luiz.alberton@ufsc.br
} 
Resumo

Mudanças em relação à prestação de serviços públicos, bem como a sua crescente demanda pela população, obrigam a atualização das práticas na administração pública, incluindo-se a aplicação de métodos de gerenciamento do setor privado, os quais têm sido exigidos em diversas normas e legislações como, por exemplo, a obrigatoriedade de manutenção de um sistema de gestão de custos. No entanto, em diversas situações, o cumprimento das novas normas e legislações parece ocorrer somente em teoria ou, alternativamente, é aplicada de forma limitada. Assim, o objetivo deste trabalho, de natureza exploratória, é verificar o custo do Serviço de Auditoria Federal do SUS na unidade de Santa Catarina - SEAUD/SC com base no método de custeio por absorção - rateio simples e comparar com os valores apresentados pelo Governo Federal para o ano de 2012. Para a realização da pesquisa utilizaram-se dados extraídos do Sistema Integrado de Administração Financeira do Governo Federal - SIAFI e de outras fontes, como relatórios de gestão e pedido de acesso à informação por intermédio do Sistema Eletrônico do Serviço de Informação ao Cidadão do Governo Federal (e-SIC). Como resultado, evidenciou-se significativa diferença em relação às informações prestadas pelo Governo Federal e o custo da prestação dos serviços segundo o método de custeio por absorção aplicado nesta pesquisa. Em resumo, de acordo com esta pesquisa, o Governo Federal desconsidera $79,61 \%$ dos custos administrativos do SEAUD/SC, o que pode causar distorções nas informações utilizadas para a tomada de decisão dos gestores públicos, bem como mascarar o custo deste serviço prestado à sociedade.

Palavras-chaves: Gestão Pública; Custo real; Gestão de custos; Absorção.

Abstract Changes in relation to the provision of public services, as well as its increasing demand by the population, require updating practices in public administration, including the application of management methods from the private sector, which have been required in various laws and norms, for example, the requirement for maintenance of a system management costs. However, in many situations, compliance with the new rules and laws seems to occur only in theory or, alternatively, is applied to a limited form. The objective of this study, exploratory in nature, is to check the real cost of the Federal Audit Service SUS unit located in Santa Catarina - SEAUD / SC based on absorption costing method - simple apportionment and compare with the report provided by the Federal Government for the year 2012. To carry out the research were used data extracted from the Sistema Integrado de Administração Financeira do Governo Federal - SIAFI and other sources, such as management reports and request for access to information via the Sistema Eletrônico do Serviço de Informação ao Cidadão do Governo Federal (e-SIC). As a result, revealed a significant difference in relation to the information provided by Federal Government and the established cost of services according the absorption costing method applied in this research. In summary, according to this study, the Federal Government 
ignores $79,61 \%$ of the administrative costs of SEAUD/SC, which can distort the information used for decision making of public managers, as well as mask the cost of this service to society.

Keywords: Public administration; Real cost; Cost management; Absorption costing method.

Resumen Los cambios en relación con la prestación de los servicios públicos, así como su creciente demanda por población, requieren prácticas de actualización en la administración pública, incluyendo la aplicación de métodos de gestión del sector privado, que se ha requerido en diversas leyes y normas como, por ejemplo, el requisito para el mantenimiento de un sistema de costes de gestión. Sin embargo, en muchas situaciones, el cumplimiento de las nuevas normas y leyes parece ocurrir sólo en la teoría o, alternativamente, se aplica de manera limitada. El objetivo de este estudio, de carácter exploratorio, es comprobar el coste de lo Serviço de Auditoria Federal do SUS unidad en Santa Catarina - SEAUD/SC basado en el método de costeo por absorción - evaluación sencilla y comparar con las cifras proporcionadas por el Gobierno Federal para el año 2012. Para la investigación utilizó datos extraídos del Sistema Integrado de Administração Financeira do Governo Federal - SIAFI y de otras fuentes, como los informes de gestión y solicitud de acceso a la información a través del Sistema Eletrônico do Serviço de Informação ao Cidadão do Governo Federal (e- SIC). Como resultado de, se hizo evidente una diferencia significativa en relación con la información proporcionada por el Gobierno Federal y el costo de la prestación de servicios segundo el método de costeo por absorción aplicada en esta investigación. En resumen, según esta investigación, el Gobierno Federal no tiene en cuenta $79,61 \%$ de los gastos administrativos de SEAUD/SC, lo que puede distorsionar la información utilizada para la toma de decisiones de los gestores públicos, así como enmascarar el coste de este servicio a la sociedad.

Palabras Clave: Gestión Pública; Costo real; Gestión de costes; Costeo por absorción. 


\section{Introdução}

A crítica em relação a gestão da máquina pública nas últimas décadas resultou em processos que motivaram o Estado a adotar métodos utilizados, até então, somente no setor privado (Ensslin et al., 2013). Desta forma, mudanças em relação a legislação e cultura organizacional determinaram a introdução do gerencialismo no setor público, visando a desburocratização do sistema público e almejando resultados durante a gestão (Osborne, 1993). Com o gerencialismo esperava-se que as necessidades da sociedade fossem satisfeitas e que o Estado mantivesse controle total sobre os seus recursos, maximizando-os e gerindo-os de forma eficiente (Paula, 2005; Van Helden, 2005; Verbeteen, 2011).

A implantação do gerencialismo na gestão pública, segundo Van Helden (2005) acontece, aparentemente, como uma convergência teórica e não é aplicada na prática, ou então é realizada de forma limitada. Assim, as informações geradas podem ser pouco relevantes, uma vez que são realizadas somente para atender a certas normas e não são utilizadas para o seu real objetivo de fornecimento de informações úteis para o gestor. Verifica-se situações constantes em que as despesas superam as receitas, iniciando-se políticas de contenção de gastos, a fim de equilibrar as contas (Almeida et al., 2009).

No entanto, as informações acerca dos gastos públicos estão organizadas para atender as necessidades da administração financeira (fluxo de caixa). As informações geradas pela contabilidade estão direcionadas a apurar o quanto foi gasto em um determinado programa de governo e/ou projeto/atividade em um determinado período, mas não possuem um sistema estruturado que apresente o custo real do serviço prestado (Alonso, 1999; Rezende et al., 2010). Neste sentido, um modelo de custeio que incorpore tanto os custos diretos quanto os indiretos para um determinado serviço, como o denominado "custeio por absorção" pode apresentar um valor mais próximo do que, efetivamente, é gasto numa determinada organização.

Portanto, faz-se fundamental para o gestor público conhecer os custos dos serviços prestados, por meio de um sistema estruturado de gestão, uma vez que estas informações são imprescindíveis no processo de tomada de decisão sobre o uso dos recursos públicos, apurando as relações entre os recursos efetivamente utilizados, serviços entregues à população e os benefícios decorrentes destes (Borges et al., 2013). Desta forma, a mensuração e o controle dos custos na administração pública são etapas de extrema importância, e devem ser realizadas de forma efetiva para maximizar seus resultados. 
Diante da demanda por informações de custos no setor público, o Governo Federal brasileiro criou em 09 de março de 2011, por intermédio da portaria $n^{\circ} 157$ da Secretaria do Tesouro Nacional - STN, o Sistema de Custos do Governo Federal. Porém, este sistema não está efetivamente implantado e não oferece o custo dos serviços prestados pela União. Mas, assim como a norma citada, existem diversas outras normas evidenciando a obrigatoriedade da aplicação do gerenciamento de custos no setor público, no entanto faltam estudos práticos sobre o assunto, acarretando em dúvidas por parte dos gestores públicos ao aplicarem tais métodos (Almeida et al., 2009).

Tal problema é verificado na unidade descentralizada do Serviço de Auditoria do Ministério da Saúde em Santa Catarina - SEAUD/SC, onde não há apuração dos custos do serviço prestado e apresenta-se apenas os gastos deste serviço em dois programas de governo: Administração da Unidade Nacional, que inclui alguns custos administrativos; e Auditoria do SUS, que inclui as diárias e passagens utilizadas na prestação do serviço de auditoria. A forma como os gastos do serviço de auditoria são apresentados na prestação de contas do Ministério da Saúde não é suficiente para conhecer o custo total do Serviço de Auditoria Federal do SUS em Santa Catarina, sendo que os custos administrativos, com depreciação e com pessoal não são individualizados para cada serviço prestado pelo Ministério da Saúde.

Diante do exposto, formulou-se a seguinte questão-problema: qual o custo do Serviço de Auditoria Federal do SUS na unidade descentralizada de Santa Catarina, com base no método de custeio por absorção - rateio simples, em comparação ao apresentado pelo Governo Federal para o ano de 2012?

Para responder tal pergunta de pesquisa, definiu-se como objetivo geral deste trabalho verificar o custo do Serviço de Auditoria Federal do SUS na unidade descentralizada de Santa Catarina no ano de 2012, com base no método de custeio por absorção - rateio simples, comparativamente ao apresentado pelo Governo Federal. Adicionalmente, são definidos como objetivos específicos da pesquisa: (i) aplicar o método de custeio por absorção aos dados do exercício de 2012; e (ii) comparar os resultados com os valores fornecidos pelo Governo Federal referente ao exercício 2012.

O trabalho justifica-se pela relevância para o setor público, onde se fornece um norte para a aplicação de ferramentas de contabilidade gerencial na administração pública, como por exemplo o método de custeio por absorção, amplamente utilizado no meio empresarial. A utilização correta de tais ferramentas pode oferecer uma maior eficiência do emprego dos recursos do Estado e, consequentemente, em tomada de decisões embasadas em informações mais confiáveis, não levando em consideração somente as informações contidas nos tradicionais relatórios de fluxo de caixa. Por 
consequência, verifica-se a extrema importância de calcular o custo real das atividades exercidas pelo governo (Rezende et al., 2010).

Além disso, o presente estudo pretende enfatizar a importância da apuração dos custos reais no setor público bem como evidenciar a importância da geração de informações de qualidade prestadas aos usuários deste segmento.

\section{Referencial Teórico}

São crescentes as divulgações referentes à ineficiência da gestão pública e a insatisfação por parte da sociedade pelo não cumprimento de suas necessidades. Para melhorar os resultados e a aplicação dos recursos, foram aplicados métodos oriundos da iniciativa privada para resolver tais problemas. Esses métodos, vinculados à onda do gerencialismo na gestão pública, objetivam realizar a gestão por resultados, reduzem a falta de foco e transparência (Paula, 2005; Valmorbida et al., 2012).

Dentre os métodos, o gerenciamento de custos se mostra de suma importância em virtude dos constantes déficits apurados nas contas do governo, que ocasionam em políticas de cortes nos gastos públicos. Para os gestores, não basta apenas saber quanto é o gasto na produção de bens e de serviços, é importante conhecer os custos e os resultados por eles gerados, e se há formas de reduzir os custos para a geração dos mesmos produtos e serviços (Rezende et al. 2010; Van Helden, 2005; Verbeteen, 2011).

A obrigatoriedade pela contabilização dos custos no setor público vigora na legislação há bastante tempo. A Lei n. 4.320/64 prevê a aplicação de sistema de custos em seu artigo n. 99 aos serviços industriais. O Decreto-lei n. 200/67 estendeu a obrigatoriedade a toda administração pública federal, buscando evidenciar os resultados da gestão. Mais recente, a Lei de Responsabilidade Fiscal (Lei Complementar n. 101/2000) determina que toda a administração pública deve manter um sistema de custos que admita a avaliação e o acompanhamento da gestão orçamentária, financeira e patrimonial. Posteriormente, a Portaria STN n. 157/2011 definiu a criação do Sistema de Custos do Governo Federal.

Além dessas, ainda existem as Normas Brasileiras de Contabilidade Aplicadas ao Setor Público (NBCASP), que desde 2008 tentam alinhar as exigências das Normas Internacionais de Contabilidade do Setor Público (International Public Sector Accounting Standard). Dentre os pronunciamentos, incluem-se a obrigatoriedade de aplicação de subsistemas de custos, conforme a NBC T 16.11 (Carneiro et al., 2012). 
Apesar de todas as normativas referentes à determinação sobre o uso de métodos de controle de custos são raros os casos em que as organizações públicas utilizam-se dos métodos gerenciais para administrar os custos de seus serviços. Segundo Van Helden (2005), a utilização desses métodos é limitada ou até mesmo teórica. O estudo realizado por Almeida et al. (2009) já evidenciara o baixo número de publicações acerca de estudos sobre gestão de custos na esfera governamental e, por consequência disto, são ainda mais raras as apresentações de casos práticos sobre a aplicação destes métodos gerenciais.

Verifica-se que o governo não sabe quanto custa o serviço prestado, devido à precária utilização dos seus sistemas disponíveis. Conhecendo-se quanto custam os serviços prestados os gestores públicos podem vir a promover a redução dos custos e ainda melhorarem a qualidade na prestação desses serviços (Alonso, 1999).

Com a criação do Sistema de Custos do Governo Federal esperava-se que esse panorama se alterasse, porém não se observa mudanças verificandose os relatórios publicados pelo governo, sobretudo no objeto de pesquisa, o setor de Auditoria do SUS em Santa Catarina, onde a apuração dos custos ainda está sendo feita somente com base em programas de trabalho. Desta forma, os custos administrativos são alocados no programa de administração nacional do Fundo Nacional de Saúde, não sendo possível a separação dos custos por tipo de serviço prestado e, consequentemente, o custo do SEAUD/SC não é conhecido pelos gestores e pela sociedade.

Face aos problemas apontados, torna-se extremamente importante a existência e plena utilização de métodos para estimar o custo real dos serviços prestados pelo Estado, para que então sejam tomadas decisões embasadas em informações confiáveis e fidedignas. Neste sentido, algumas pesquisas se apresentam no sentido de oferecer respostas a questões pontuais relacionadas a esfera governamental.

Conforme evidenciado por Almeida et al. (2009) são raras as pesquisas com cunho prático sobre a aplicação de métodos de gestão de custos na esfera governamental, mas é possível encontrar trabalhos em relação a importância da existência e da utilização destes métodos pela gestão pública.

Verbeeten (2011) realizou uma pesquisa com gestores financeiros de organizações públicas da Holanda. A pesquisa envolveu questionários almejando validar a alegação de que o desenvolvimento do setor tem aumentado a procura pela utilização de informações da gestão de custos. Os resultados encontrados foram que os sistemas de gerenciamento de custos são utilizados para satisfazer as imposições legais e apresentar às partes interessadas, ao invés de utilizá-las internamente para fins gerenciais. 
O artigo de Curi et al. (2012) buscou estudar a gestão de custos - sua alocação e mensuração - em um Instituto Federal de Ensino Superior, de acordo com as atribuições do setor de Controladoria, por meio de entrevistas, questionários e análise documental. O resultado permitiu, aos pesquisadores, conhecer o total do custo anual do objeto estudado, podendo ainda auxiliar no processo decisório da organização.

Arnaboldi e Lapsley (2005) realizaram uma pesquisa relativa a implementação do método de custeio $A B C$ no ambiente da saúde pública. Os resultados evidenciaram que apesar do sucesso no funcionamento do sistema, o impacto causado foi limitado. Evidenciou-se ainda a necessidade do apoio da alta administração e de toda uma equipe preparada para o pleno funcionamento do método $A B C$.

Carneiro et al. (2012) realizaram uma pesquisa em relação as publicações sobre o tema custos no setor público nos congressos da ANPAD, ABCustos e da USP. Verificou-se que o maior número de publicações, dentre os métodos discutidos, tratavam do custeio $A B C$, e em segundo lugar o custeio por absorção.

Almeida et al. (2009), por meio da pesquisa em relação à utilização da gestão de custos na saúde pública, identificaram que é rara a existência de setores especializados no desenvolvimento da gestão de custos nos órgãos, mas que os gestores julgam que seria importante a existência deste setor em seus órgãos.

Como se pode observar, algumas pesquisas, de algum modo, aplicaram técnicas estruturadas para a apresentação de resultados práticos sobre a questão dos custos no setor público. Independentemente dos diversos modelos de custeio existentes, tanto na literatura quanto em termos de aplicação prática, o presente estudo se utiliza do método de custeio por absorção, que consiste no rateio de todos os custos de produção aos produtos e serviços, quer sejam diretos ou indiretos, para a verificação do efetivo custo do serviço de Auditoria Federal do SUS na unidade de Santa Catarina - SEAUD/SC, cujos procedimentos metodológicos são descritos a seguir.

\section{Procedimentos metodológicos}

A presente pesquisa, em relação à natureza de seu objetivo, caracterizase como exploratória. Trata de uma aplicação pouco abordada, envolvendo pesquisa em um estudo de caso, aplicando um método de custeio na organização estudada, com objetivo de verificar diferenças entre o método adotado pelo governo e o método utilizado pelos pesquisadores (Gil, 1999). 
Quanto à natureza do artigo, a pesquisa classifica-se como prática, caracterizada como um estudo de caso, pois analisa profundamente a instalação do modelo de custeio por absorção em um determinado local, neste caso evidenciado com a seccional de auditoria do SUS em Santa Catarina (Alavi \& Carlson, 1992).

Em relação à lógica, a pesquisa caracteriza-se como indutiva, uma vez que se trata de um estudo em uma estrutura particular, em que não há uma conclusão inquestionável, pois o resultado apresenta-se construído somente para o objeto estudado (Ensslin et al., 2013).

A coleta de dados da pesquisa utiliza os dados primários e os dados secundários. A utilização dos dados referentes ao setor de auditoria do SUS em Santa Catarina do período de 2012 e as delimitações definidas pelos próprios pesquisadores caracterizam a utilização de dados primários, como por exemplo, a definição da utilização do método de custeio por absorção - rateio simples. A partir da análise dos documentos e relatórios utilizados pela pesquisa, evidencia-se a utilização de dados secundários, que são obtidos a partir de sistemas como o SIAFI, e a partir de solicitações para as áreas competentes (Richardson, 1999).

Quanto à abordagem do problema, em relação ao processo de pesquisa, o trabalho é caracterizado como qualitativo. A abordagem qualitativa fica evidenciada na comparação do modelo proposto pelos autores contra o apresentado pelo governo, verificando-se as diferenças e apresentando-as (Richardson, 1999).

Quanto aos procedimentos, trata-se de um estudo de caso no Setor de Auditoria do SUS em Santa Catarina, cuja coleta dos dados foi realizada por meio de documentos internos disponíveis no Setor de Auditoria. Os dados utilizados para a realização desta pesquisa foram, em partes, extraídos diretamente do sistema SIAFI e de outras fontes, como relatório de gestão e pedido de acesso a informação por intermédio do Sistema Eletrônico do Serviço de Informação ao Cidadão do Governo Federal (e-SIC).

Para apurar os custos dos serviços prestados pelo Serviço de Auditoria Federal do SUS em Santa Catarina fora necessário realizar o levantamento de todos os gastos do período e definir as formas de alocação destes custos, ou seja, utilizou-se de dados financeiros para se chegar a uma apuração por competência, em que se buscou apropriar os custos em relação ao período em que ocorreram e não quando o desembolso foi efetivado.

Inicialmente, buscou-se um estudo bibliográfico em livros, revistas, teses e dissertações e internet sobre custos no setor público. Em uma segunda etapa, fora realizado um levantamento dos custos do Serviço de Auditoria 
Federal do SUS em Santa Catarina. Logo após, os dados foram coletados e organizados, utilizando-se o método de custeio por absorção - rateio simples para apuração dos custos. Na terceira etapa, formulou-se um pedido de acesso a informação por intermédio do sistema e-SIC, onde foi solicitado o custo do Serviço de Auditoria Federal do SUS em Santa Catarina apurado pelo próprio governo para o ano de 2012.

Para finalizar, os dados foram analisados sob os aspectos predominantemente qualitativos por intermédio da comparação dos dados coletados em relação ao custo apurado pelo método de custeio por absorção e as informações prestadas pelo Governo Federal por intermédio do sistema eSIC.

\section{Apresentação e análise dos dados}

Segundo informações divulgadas no sítio eletrônico do Departamento Nacional de Auditoria do SUS - DENASUS, o Serviço de Auditoria Federal do SUS em Santa Catarina - SEAUD/SC é uma unidade descentralizada do DENASUS, responsável por acompanhar, controlar e avaliar as ações e serviços de saúde em todo o território nacional em cooperação técnica com Estados, Municípios e Distrito Federal. Sua missão é "realizar auditoria no SUS, contribuindo para qualificação da gestão, visando melhoria da atenção e do acesso às ações e aos serviços de Saúde".

As competências do Departamento Nacional de Auditoria do SUS estão descritas no artigo 35 do Decreto $N^{\circ} 7.797$ de 2012. Resumidamente, o artigo apresenta as competências do Departamento Nacional de Auditoria do SUS como as de promover o fortalecimento do Sistema Nacional de Auditoria do SUS; auditar a adequação, a qualidade e a efetividade das ações e serviços públicos de saúde, e a regularidade legal das aplicações dos recursos do SUS; estabelecer e propor diretrizes e normas para a padronização das ações de auditoria; integrar as ações e procedimentos de auditoria do Sistema Nacional de Auditoria do SUS; e, demais atividades inerentes.

O SEAUD/SC tem sede em Florianópolis no prédio pertencente ao Núcleo Estadual do Ministério da Saúde em Santa Catarina - NEMS/SC. A unidade conta com 33 servidores, sendo 16 deles de nível superior, 16 de nível médio e 1 Auxiliar operacional.

O SEAUD/SC localiza-se em um edifício de nove andares que abriga também os outros órgãos do governo federal, mas somente $03^{\circ}$ andar é utilizado pelo mesmo. A divisão dos custos de manutenção predial é feita entre os órgãos de acordo com os critérios estabelecidos nos documentos que 
regulamentam o uso do prédio pelos órgãos, bem como a divisão das despesas dos mesmos.

O NEMS/SC é a unidade descentralizada do Ministério da Saúde em Santa Catarina e também responsável pela administração do prédio onde está localizado o SEAUD/SC. A unidade é composta pela Divisão de Convênios e Gestão - DICON, Departamento de Informática do SUS - DATASUS, Serviço de Gestão de Pessoas - SEGEP e o Serviço de Auditoria de Santa Catarina SEAUD/SC.

Da área total do prédio, 54\% são utilizadas pelo NEMS/SC e apenas $11 \%$ é atribuída ao SEAUD/SC, já considerando as áreas de uso coletivo, como corredores, recepção e outras. Os serviços de limpeza e vigilância foram rateados de acordo com a área utilizada pelos setores.

Grande parte dos custos foi rateada de acordo com o número de servidores de cada setor. O número de servidores do SEAUD/SC é 33 de um total de 154 servidores do NEMS/SC, ou seja, 21,43\% do total dos servidores. Os custos que foram alocados com base neste percentual de rateio foram: água, café, açúcar, fotocópias, manutenção de elevadores, energia elétrica, água e esgoto, serviços postais, recepção e copeiragem, manutenção de computadores, central telefônica, taxa de coleta de resíduos e internet.

Os custos com a manutenção de condicionadores de ar foram rateados de acordo com o número de aparelhos alocados no SEAUD/SC, sendo 09 de um total de 59 que foram cobertos pelo referido contrato, ou seja, 15,25\% do total gasto com a manutenção de condicionadores de ar.

O contrato de locação de veículos é composto por uma parte fixa e outra parte variável. O objeto do contrato é o transporte dos servidores e documentos do NEMS/SC. O critério adotado para o rateio destes custos foi o total de quilômetros rodados para atender os servidores do serviço de auditoria. A apuração do total de quilômetros por setor foi realizada com base nas solicitações de transporte (formulário de controle interno).

Apresenta-se a seguir a Tabela 1, contendo a apuração dos custos indiretos do SEAUD/SC no ano de 2012, quais sejam aqueles que necessitam de algum critério de rateio para a sua imputação. 
Tabela 1 - Apuração dos Custos Indiretos do SEAUD/SC - exercício 2012

\begin{tabular}{|c|c|c|c|}
\hline \multicolumn{4}{|c|}{ CUSTOS INDIRETOS } \\
\hline Custo & $\begin{array}{c}\text { Critério de } \\
\text { Rateio }\end{array}$ & $\begin{array}{l}\text { Custo do } \\
\text { NEMS/SC }\end{array}$ & $\begin{array}{c}\text { Custo } \\
\text { SEAUD/SC }\end{array}$ \\
\hline Limpeza & área ocupada & $115.642,84$ & $12.720,71$ \\
\hline Vigilância & área ocupada & $163.462,00$ & $17.980,82$ \\
\hline Fotocópias & no servidores & $24.278,57$ & $5.202,90$ \\
\hline Água, Café, Açúcar & no servidores & $6.612,60$ & $1.417,08$ \\
\hline Manut. Elevadores & $\mathrm{n}^{0}$ servidores & $3.440,91$ & 398,19 \\
\hline Energia Elétrica & no servidores & $50.503,57$ & $5.844,37$ \\
\hline Água e Esgoto & $\mathrm{n}^{\circ}$ servidores & $23.261,75$ & $2.691,90$ \\
\hline Serviços Postais & $\mathrm{n}^{\circ}$ servidores & $60.901,66$ & $13.051,23$ \\
\hline Recepção e Copeiragem & $\mathrm{n}^{\circ}$ servidores & $85.532,16$ & $18.329,54$ \\
\hline Manut. Computadores & $\mathrm{n}^{0}$ servidores & $41.816,04$ & $8.961,18$ \\
\hline Central Telefônica & $\mathrm{n}^{\circ}$ servidores & $9.348,60$ & $2.003,40$ \\
\hline $\begin{array}{l}\text { Taxa de coleta de } \\
\text { Resíduos }\end{array}$ & no servidores & $12.814,93$ & $1.482,97$ \\
\hline Internet & $\mathrm{n}^{\circ}$ servidores & $2.072,47$ & 444,13 \\
\hline Manut. Cond. de ar & $\mathrm{n}^{\circ}$ de aparelhos & $10.343,59$ & $1.577,84$ \\
\hline Transporte de Servidores & Km Rodados & $245.814,70$ & $84.777,25$ \\
\hline Total & & $855.846,39$ & $176.883,50$ \\
\hline
\end{tabular}

Fonte: Dados da pesquisa.

Alguns tipos de custo, devido à natureza e a forma de controle, puderam ser atribuídos diretamente ao SEAUD/SC, uma vez que não há dúvidas sobre a quem devem ser imputados. Estes custos são apresentados na Tabela 2. 
Tabela 2 - Apuração dos Custos Diretos do SEAUD/SC - exercício 2012

\begin{tabular}{l|r}
\hline \multicolumn{2}{c}{ Custos Diretos } \\
\hline Telefone & $1.582,26$ \\
\hline Material de consumo & $1.691,12$ \\
\hline Diárias & $51.748,66$ \\
\hline Depreciação & $21.837,92$ \\
\hline \multicolumn{1}{c}{ Total } & $\mathbf{7 6 . 8 5 9 , 9 6}$ \\
\hline Fonte: Dados da pesquisa.
\end{tabular}

Os custos referentes aos serviços de telefonia são discriminados por ramais na fatura de cobrança deste serviço, então foi alocado o valor diretamente ao setor com base nos ramais que são utilizados pelos servidores SEAUD/SC.

Os custos com material de consumo foram levantados a partir do sistema de almoxarifado com base nas requisições realizadas pelo setor no ano de 2012. Logo, os custos puderam ser alocados diretamente ao setor devido ao detalhamento da informação do sistema de almoxarifado.

Em relação às diárias, os valores foram extraídos do Sistema de Diárias e Passagens do Governo Federal - SCDP. Este sistema apresenta relatórios com fácil identificação das diárias dos servidores de cada setor em um determinado período.

O custo da depreciação do período foi apurado com base nos dados extraídos do sistema de patrimônio. O inventário total dos bens móveis utilizados pelo SEAUD/SC em 31/12/2012 era de R\$218.379,22.

Tabela 3 - Apuração total dos custos do SEAUD/SC - exercício 2012

\begin{tabular}{l|r}
\hline \multicolumn{2}{c}{ Apuração dos Custos } \\
\hline Custos Diretos & $76.859,96$ \\
\hline Custos Indiretos & $176.883,50$ \\
\hline Custos com Pessoal & $3.621 .159,88$ \\
\hline Total & $\mathbf{3 . 8 7 4 . 9 0 3 , 3 4}$ \\
\hline \multicolumn{2}{|c}{ Fonte: Dados da pesquisa }
\end{tabular}

O valor do custo com pessoal foi apurado com base na Tabela de Remuneração dos Servidores Públicos Federais - caderno $n^{\circ} 59$, publicada pela Secretaria de Gestão Publica do Ministério do Planejamento, Orçamento e Gestão - MPOG. As informações de pessoal constantes no Portal da 
Transparência do Governo Federal também foram utilizadas para o cálculo do custo do pessoal do SEAUD/SC. É importante esclarecer que o valor apurado é estimado, uma vez que não foi possível o acesso ao Sistema de Pessoal do Governo Federal - SIAPE.

A apuração dos custos administrativos (custos diretos + custos indiretos) foi de $\mathrm{R} \$ 253.743,46$. Finalizada a apuração dos custos do SEAUD/SC baseado no modelo estruturado de custeio, pode-se agora comparar os custos apurados com os divulgados pelo Governo Federal no ano de 2012.

Os custos do SEAUD/SC, no ano de 2012, originaram-se de dois programas de Trabalho - PT. Abaixo se apresentam os referidos programas, bem como sua descrição cadastrada na Lei Orçamentária Anual para o ano de 2012:

1) Auditoria do Sistema Único de Saúde - Nacional: Auditoria e fiscalização da gestão do Sistema Único de Saúde nos níveis estadual e municipal, quanto à conformidade das ações e serviços de saúde, em consonância com os princípios, diretrizes e políticas do SUS e no que diz respeito ao uso dos recursos financeiros transferidos pelo MS a cada esfera de governo, atuando de forma preventiva e educativa com a implementação de parcerias e rede integrada de atuação.

2) Administração da Unidade Nacional: Essas despesas compreendem: serviços administrativos; pessoal ativo; manutenção e uso de frota veicular, própria ou de terceiros por órgãos da União; manutenção e conservação de imóveis próprios da União, cedidos ou alugados, utilizados pelos órgãos da União; tecnologia da informação, sob a ótica meio, incluindo o apoio ao desenvolvimento de serviços técnicos e administrativos; despesas com viagens e locomoção (aquisição de passagens, pagamento de diárias e afins); sistemas de informações gerenciais internos; estudos que têm por objetivo elaborar, aprimorar ou dar subsídios à formulação de políticas públicas; promoção de eventos para discussão, formulação e divulgação de políticas, etc.; produção e edição de publicações para divulgação e disseminação de informações sobre políticas públicas e demais atividades-meio necessárias à gestão e administração da unidade.

Até 2013, a apuração dos custos do serviço das unidades descentralizadas de auditoria federal do SUS se limita, em sua quase totalidade, em gastos com diárias e passagens para os servidores que operacionalizam as auditorias. Estas diárias e passagens são alocadas ao primeiro programa, enquanto que todos os demais custos administrativos, que concentram um maior volume de gastos, são alocados no segundo programa. 
Ao Programa 1 são alocados somente os custos relacionados ao serviço de auditoria, já no Programa 2 são alocados os custos administrativos de todos os serviços atrelados ao Fundo Nacional de Saúde, entre eles citamos: Serviços de Auditoria - SEAUD, Serviço de Informática - DATASUS, Serviço de Prestação de Contas e Convênios - DICON, entre outros.

O Relatório Anual de Gestão (RAG) do NEMS/SC referente ao exercício de 2012 informa que o custo do SEAUD/SC alocado ao programa "Auditoria do Sistema Único de Saúde - Nacional" foi de R\$51.748,66. Ao observar a Tabela 2 , conclui-se que este valor é exatamente o valor gasto com diárias dos Servidores do SEAUD/SC, ou seja, neste programa de trabalho só está sendo alocado o custo da diária, e os demais custos estão alocados no programa "Administração da Unidade Nacional".

Do total dos custos administrativos, excluindo o valor do custo com pessoal, apenas $20,39 \%$ está sendo alocado no programa de trabalho "Auditoria do Sistema Único de Saúde", enquanto que os demais 79,61\% estão sendo alocados no programa de trabalho "Administração da Unidade Nacional". O relatório de Gestão apresenta os custos deste programa pelo valor total e não segregado por setor e/ou serviço, fator este que distorce a informação sobre o real custo do SEAUD/SC.

Quando questionado, por intermédio do e-SIC, sobre o custo do SEAUD/SC no exercício de 2012, o DENASUS informou que o custo de auditoria do SUS foi de $R \$ 68.711,17$, sendo que deste valor, $R \$ 16.962,51$ se referem à compra de material permanente e, por tratar-se de investimento, este valor não entra no cálculo do custo do serviço prestado, apenas a depreciação, de acordo com princípio contábil da competência. Então, o valor do serviço prestado informado pelo e-SIC é de R\$51.748,66 (valor das diárias).

A resposta do questionamento supracitado também considerou como custo do SEAUD/SC o valor das despesas com pessoal, no entanto, destacamos que o valor do custo do pessoal do SEAUD/SC não foi discriminado no RAG do NEMS/SC no ano de 2012.

A Tabela 4 apresenta o comparativo entre os custos apurados pelo método de custeio por absorção, elaborado pelos autores desta pesquisa, e os custos informados pelo Ministério da Saúde. 
Tabela 4 - Comparativo entre o custo do SEAUD/SC apurado pelo método de custeio por absorção - rateio simples, e o custo apurado por programas pelo Ministério da Saúde - exercício 2012.

\begin{tabular}{|c|c|c|c|c|c|c|c|}
\hline \multirow{2}{*}{$\begin{array}{l}\text { Exercício } 2012 \\
\text { Custos }\end{array}$} & \multicolumn{3}{|c|}{$\begin{array}{c}\text { Apuração dos custos com base } \\
\text { no método de custeio por } \\
\text { absorção - autores }\end{array}$} & \multicolumn{4}{|c|}{$\begin{array}{c}\text { Apuração dos custos com base } \\
\text { em programas de trabalho - } \\
\text { Ministério da Saúde }\end{array}$} \\
\hline & Diretos & Indiretos & Total & $\begin{array}{c}\text { Program } \\
\text { a }\end{array}$ & $\begin{array}{l}\text { Custos } \\
\text { Totais }\end{array}$ & $\begin{array}{c}\text { Const } \\
\text { a no } \\
\text { RAG } \\
\text { ? }\end{array}$ & $\begin{array}{l}\text { Informa } \\
\text { do no e- } \\
\text { SIC? }\end{array}$ \\
\hline Limpeza & & $12.720,71$ & $12.720,71$ & P2 & & Não & Não \\
\hline Vigilância & & $17.980,82$ & $17.980,82$ & $\mathrm{P} 2$ & & Não & Não \\
\hline Fotocópias & & $5.202,90$ & $5.202,90$ & P2 & & Não & Não \\
\hline Água, Café, Açúcar & & $1.417,08$ & $1.417,08$ & $\mathrm{P} 2$ & & Não & Não \\
\hline Manut. Elevadores & & 398,19 & 398,19 & $\mathrm{P} 2$ & & Não & Não \\
\hline Energia Elétrica & & $5.844,37$ & $5.844,37$ & $\mathrm{P} 2$ & & Não & Não \\
\hline Água e Esgoto & & $2.691,90$ & $2.691,90$ & $\mathrm{P} 2$ & & Não & Não \\
\hline Serviços Postais & & $13.051,23$ & $13.051,23$ & $\mathrm{P} 2$ & & Não & Não \\
\hline $\begin{array}{l}\text { Recepção } \\
\text { Copeiragem }\end{array}$ & & $18.329,54$ & $18.329,54$ & P2 & & Não & Não \\
\hline $\begin{array}{l}\text { Manut. } \\
\text { Computadores }\end{array}$ & & $8.961,18$ & $8.961,18$ & $\mathrm{P} 2$ & & Não & Não \\
\hline Central Telefônica & & $2.003,40$ & $2.003,40$ & $\mathrm{P} 2$ & & Não & Não \\
\hline $\begin{array}{l}\text { Taxa de coleta de } \\
\text { Resíduos }\end{array}$ & & $1.482,97$ & $1.482,97$ & $\mathrm{P} 2$ & & Não & Não \\
\hline Internet & & 444,13 & 444,13 & $\mathrm{P} 2$ & & Não & Não \\
\hline Manut. Cond. de ar & & $1.577,84$ & $1.577,84$ & P2 & & Não & Não \\
\hline $\begin{array}{ll}\text { Transporte } & \text { de } \\
\text { Servidores } & \end{array}$ & & $84.777,25$ & $84.777,25$ & $\mathrm{P} 2$ & & Não & Não \\
\hline Telefone & $1.582,26$ & & $1.582,26$ & $\mathrm{P} 2$ & & Não & Não \\
\hline Material de consumo & $1.691,12$ & & $1.691,12$ & $\mathrm{P} 2$ & & Não & Não \\
\hline Diárias & $\begin{array}{r}51.748,6 \\
6 \\
\end{array}$ & & $51.748,66$ & $\mathrm{P} 1$ & $\begin{array}{r}51.748,6 \\
6 \\
\end{array}$ & Sim & Sim \\
\hline Depreciação & $\begin{array}{r}21.837,9 \\
2 \\
\end{array}$ & & $21.837,92$ & $\mathrm{P} 2$ & & Não & Não \\
\hline Soma custos adm. & $\begin{array}{r}76.859,9 \\
6 \\
\end{array}$ & \begin{tabular}{|r|}
$176.883,5$ \\
1 \\
\end{tabular} & \begin{tabular}{|l|}
$253.743,47$ \\
\end{tabular} & & $\begin{array}{r}51.748,6 \\
6 \\
\end{array}$ & & \\
\hline Pessoal & & & \begin{tabular}{|r|}
$3.621 .159,8$ \\
8 \\
\end{tabular} & $\mathrm{P} 1$ & & Não & Sim \\
\hline Total dos custos & $\begin{array}{r}76.859,9 \\
6\end{array}$ & $\begin{array}{r}176.883,5 \\
1 \\
\end{array}$ & \begin{tabular}{|r|}
$3.874 .903,3$ \\
5 \\
\end{tabular} & & $\begin{array}{r}51.748,6 \\
6\end{array}$ & & \\
\hline
\end{tabular}

Fonte: Dados da pesquisa 
Ao analisar a Tabela 4, fica evidente que somente o custo das diárias é considerado pelo Ministério da Saúde como custo do SEAUD/SC, e que os custos administrativos não são divulgados pelo RAG e nem pelo e-SIC. A qualidade da informação sobre os custos dos serviços prestados pelo governo ainda é limitada, nem mesmo os gestores públicos tem o conhecimento sobre o real custo do SEAUD/SC.

\section{Conclusões}

Identificou-se que o Ministério da Saúde não apura o custo real do serviço de auditoria e que os custos são alocados em dois programas de trabalho, um deles específico para auditoria e outro de caráter geral em que são alocados os serviços administrativos do Fundo Nacional de Saúde, sem separação dos custos por tipo de serviço.

Os custos do SEAUD/SC referente ao exercício de 2012 foram apurados com base no método de custeio por absorção - rateio simples e apresentados na Tabela 1 (apuração dos custos indiretos e apresentação dos critérios de rateio) e na Tabela 2 (apuração dos custos diretos). Os custos administrativos (custos diretos + custos indiretos) totalizaram $\mathrm{R} \$ 253.743,46$. Os custos com pessoal foram estimados com base na remuneração de pessoal divulgada pelo governo federal, já que não foi possível o acesso aos dados do SIAPE, totalizando $\mathrm{R} \$ 3.621 .159,88$.

Já no Relatório Anual de Gestão do NEMS/SC os custos atribuídos ao SEAUD/SC representam apenas $20,39 \%$ do total dos custos administrativos apurados nesta pesquisa, ou seja, o relatório apresenta apenas os custos com diárias para os servidores que operacionalizaram as auditorias no ano de 2012. Os custos de pessoal não foram informados por setor, mas pelo total gasto com pessoal do NEMS/SC.

Em resposta ao pedido de informação formulado pelos autores, por intermédio do e-SIC, o DENAUS informou que o custo do SEAUD/SC foi de R\$ $68.711,17$. Porém, parte deste valor, $\mathrm{R} \$ 16.962,51$, refere-se à compra de material permanente e, por tratar-se de investimento, este valor não deve ser incluído no cálculo do custo do serviço prestado. Logo, o valor do custo dos

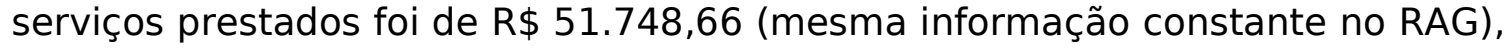
no entanto o DENASUS considerou o custo de pessoal na resposta formalizada.

Conclui-se, portanto, que o Ministério da Saúde, na apuração dos custos do SEAUD/SC, considera apenas $20,39 \%$ dos custos administrativos (exceto custo com pessoal) que foram apurados pelo método de custeio por absorção rateio simples $(R \$ 253.743,46)$. O Ministério da Saúde aloca estes custos 
(custos com diárias) no programa de trabalho "Auditoria do Sistema Único de Saúde", enquanto que os demais $79,61 \%$ estão sendo alocados no programa de trabalho "Administração da Unidade Nacional" e não são divididos entre os tipos de serviço prestados pelo Fundo Nacional de Saúde.

Diante da comparação entre os custos apurados nesta pesquisa e os custos divulgados pelo governo, nota-se que os gestores não conhecem o custo real do SEAUD/SC, pois desconsideram quase $4 / 5$ dos custos administrativos que são atribuídos ao Programa Nacional da Unidade. Esta forma de apuração dos custos causa distorções nas informações utilizadas para tomada de decisão dos gestores públicos, bem como mascara o custo deste serviço prestado à sociedade.

Conforme exposto, fica evidente a diferença do custo real calculado por essa pesquisa e o que é apresentado via relatório. Confirma-se, então, o que é descrito por Van Helden (2005). O sistema de custos limita-se a ao apresentar informações, e muitas vezes nem mesmo os gestores conhecem o custo real dos serviços prestados por seus setores.

Também esperado, confirmou-se a afirmação de Almeida et al. (2009) sobre o pobre conteúdo na literatura sobre gestão de custos na esfera governamental e, sobretudo, a falta de estudos sobre a aplicação real da apuração de custos, o qual este trabalho objetiva a preencher tal lacuna. Salienta-se que a transparência dos custos apurados pelo Governo Federal parece apenas cumprir uma determinação legal, desconsiderando a qualidade do que é divulgado. Desta forma, demonstra-se que existe uma grande necessidade para o referido setor, sendo necessário inovar a metodologia de cálculo dos custos na gestão pública, aproximando o custo real das atividades com o que é divulgado pelo governo.

Orienta-se para futuros trabalhos uma análise completa de toda a estrutura de um ministério, por exemplo. Ou ainda, a comparação de um custo real, utilizando-se das metodologias $A B C$ e absorção simultaneamente.

\section{Referências Bibliográficas}

Alavi, Maryam., \& Carlson, Patricia (1992). "A review of MIS research and disciplinary development". Journal of Management Information Systems, 8(4), 45-62. 
Almeida, André G., \& Borba, José A., \& Flores, Luiz C. S. (2009). “A utilização das informações de custos na gestão da saúde pública: um estudo preliminar em secretarias municipais de saúde do estado de Santa Catarina". Revista de Administração Pública, Rio de Janeiro, 43(3), 579-607.

Alonso, Marcos (1999). "Custos no serviço público". Revista do Serviço Público, v. 50 , n. 1 , p. 37-63.

Arnaboldi, Michela., \& Lapsley, Irvine (2005). "Activity Based Costing in healthcare: a UK case study". Research in healthcare financial management, 10(1), 61-75.

Borges, Thiago B., \& Mario, Poueri D. C., \& Carneiro, Ricardo (2013). “A implementação do sistema de custos proposto pelo governo federal: uma análise sob a ótica institucional". Revista de Administração Pública, Rio de Janeiro, 47(2), 469-492.

Brasil. Decreto Lei n. 200 de 25 de fevereiro de 1967. Dispõe sobre a organização da Administração Federal, estabelece diretrizes para a Reforma Administrativa e dá outras providências. Brasília, DF. Disponível na internet em: http://www.planalto.gov.br/ccivil_03/decretolei/del0200.htm [Acesso em 12 mai. 2013].

Brasil. Decreto n. 7.797 de 30 de agosto de 2012. Aprova a Estrutura Regimental e o Quadro Demonstrativo dos Cargos em Comissão e das Funções Gratificadas do Ministério da Saúde. Brasília, DF. Disponível na internet em: https://www.planalto.gov.br/ccivil_03/_ato20112014/2012/decreto/d7797.htm [Acesso em 14 mai. 2013].

Brasil. Lei n. 4.320 de 17 de março de 1964. Institui normas gerais de direito financeiro para elaboração e controle dos orçamentos e balanços da União, dos estados, dos municípios e do Distrito Federal. Brasília, DF. Disponível na internet em: http://www.planalto.gov.br/ccivil_03/leis/L4320.htm [Acesso em 10 mai. 2013]

Brasil. Lei Complementar n. 101 de 04 de maio de 2000. Estabelece normas de finanças públicas voltadas para a responsabilidade na gestão fiscal e dá outras providências. Brasília, DF. Disponível na internet em: http://www.planalto.gov.br/ccivil_03/leis/lcp/lcp101.htm [Acesso em 12 mai. 2013].

Brasil. Portaria no 157 da STN de 09 de março de 2011. Dispõe sobre a criação do Sistema de Custos do Governo Federal. Brasília, DF. Disponível na internet

em: 
http://www3.tesouro.gov.br/legislacao/download/contabilidade/PortSTN_157 _09mar2011.pdf [Acesso em 10 mai. 2013].

Carneiro, Alexandre F., \& Silva Neto, José M., \& Locks, Rosilene., \& Santos, Maria M. A. (2012). “Custos na Administração Pública: revisão focada na publicação de artigos científicos a partir da promulgação da Lei de Responsabilidade Fiscal". Revista Contemporânea de Contabilidade, 9(18), 3-22.

Curi, Maria A., \& Benedicto, Gideon C., \& Nuintin, Adriano A. \& Nogueira, Leandro R. T. (2012). “Mensuração e alocação de custos no setor público de acordo com as atribuições da controladoria: Caso de uma Instituição Federal de Ensino Superior". Anais do XIX Congresso Brasileiro de Custos. Bento Gonçalves, RS, Brasil.

Paula, Ana P. P. de. (2005). “Administração pública brasileira entre o gerencialismo e a gestão social". Revista de Administração de Empresas, n. 1, p. 36-49.

Ensslin, Sandra R., \& Ensslin, Leonardo., Lacerda, Rogerio T. O., \& Matos, Lucas S. (2013). "Evidenciação do estado da arte do tema avaliação do desempenho na regulação de serviços públicos segundo a percepção dos pesquisadores". Gestão Pública: Práticas e Desafios, 4(7).

Gil, Antonio C. (1999). Métodos e técnicas de pesquisa social. São Paulo: Atlas.

Lacerda, Rogério T. O., \& Ensslin, Leonardo., \& Ensslin, Sandra R. (2012). “Uma análise bibliométrica da literatura sobre estratégia e avaliação de desempenho". Gestão \& Produção, 19(1), 59-78.

Osborne, David (1993). "Reinventing government". Public Productivity \& Management Review, 349-356.

Rezende, Fernando., \& Cunha, Armando., \& Bevilacqua, Roberto (2012). "Informações de custos e qualidade do gasto público: lições da experiência internacional". Revista de Administração Pública, 44(4), 959-992.

Richardson, Roberto J. (1999). Pesquisa social: métodos e técnicas. Atlas.

Rosa, Fabricia S., \& \& Ensslin, Sandra R., \& Ensslin, Leonardo., \& Lunkes, Rogerio J. (2011). "Gestão da evidenciação ambiental: um estudo sobre as potencialidades e oportunidades do tema. Engenharia Sanitária Ambiental", 16(1), 157-166.

Valmorbida, Sandra M. I., \& Ensslin, Sandra R., \& Ensslin, Leonardo., \& Bortoluzzi, Sandro C. (2012). “Gestão Pública com foco em resultados: 
Evidenciação de oportunidades de pesquisa". CAP Accounting and Management, 5(5).

Van Helden, G. Jan (2005). "Researching public sector transformation: the role of management accounting". Financial Accountability \& Management, 21(1), 99-133.

Verbeeten, Frank H. (2011). "Public sector cost management practices in The Netherlands". International Journal of Public Sector Management, 24(6), 492-506.

Recebido em 10/03/2013 Aceito em 08/09/2013. 